\title{
HUBUNGAN KEBIJAKAN PROGRAM INDONESIA SEHAT DENGAN PENDEKATAN KELUARGA TERHADAP ANGKA KEMATIAN BAYI (AKB) DI KEC. KARANG BARU KAB. ACEH TAMIANG
}

\author{
Relationship of Health Indonesia Program Policy with The Family Approach to \\ The Infant Mortality Rate in Karang Baru Sub District, \\ Aceh District
}

\author{
Zulfanda Manik, Muhammad Badiran, Anto J. Hadi \\ Institut Kesehatan Helvetia Medan \\ zulfandamanik15@gmail.com
}

\begin{abstract}
ABSTRAK
Program Indonesia Sehat merupakan salah satu program yang bertujuan untuk meningkatkan kualitas hidup manusia Indonesia, meningkatkan derajat kesehatan dan status gizi masyarakat melalui upaya kesehatan dan pemberdayaan masyarakat yang didukung dengan perlindungan finansial dan pemerataan pelayanan kesehatan. Tujuan penelitian ini adalah untuk menganalisishubungan kebijakan program indonesia sehat dengan pendekatan keluarga terhadap angka kematian bayidi Kecamatan Karang Baru Kabupaten Aceh Tamiang.Jenis penelitian ini merupakan surveianalitik dengan rancangan cross sectional study. Penelitian dilakukan di Kecamatan Karang Baru Kabupaten Aceh Tamiang dengansampel 66 ibu yang memiliki balita yang diambil secara simple random sampling. Analisis datadigunakan uji chi-square dan regresi logistik.Berdasarkan hasil penelitian diketahui bahwa Angka Kematian Bayi berhubungan dengan keluarga yang mengikuti Keluarga Berencana $(p=0,020)$, ibu melakukan persalinan di fasilitas kesehatan $(p=0,024)$, bayimendapatimunisasidasarlengkap $(p=0,006)$, pemanfaatan( $A S I)$ eksklusif $(p=0,03$ 8), pemantauan pertumbuhan balita $(p=0,000)$. Kesimpulan diperolehbahwafaktor yang berhubungan dengan angka kematian bayi adalah keluarga yang mengikuti Keluarga Berencana, ibu melakukan persalinan di fasilitas kesehatan, bayi mendapat imunisasi dasar lengkap, pemanfaatan (ASI) eksklusif, pemantauan pertumbuhan balita. Diharapkan agar dapat menjadi bahan dan masukan dalam pengambilan kebijakan program Indonesia Sehat dengan Pendekatan Keluarga bahwa kesehatan merupakan hak masyarakat
\end{abstract}

\section{Kata Kunci : Kebijakan Program Indonesia Sehat, Angka Kematian Bayi}

\begin{abstract}
The Healthy Indonesia Program is one program that aims to improve the quality of life of Indonesian people, improve the health status and nutritional status of the community through health efforts and community empowerment supported by financial protection and equitable distribution of health services. The general objective of this research is to analyze the policy relationship between the Healthy Indonesia Program and the Family Approach to Infant Mortality Rate (IMR) in Karang Baru Subdistrict, Aceh Tamiang Regency. This type of research is an analytic survey with a cross sectional study design. The study was conducted in Karang Baru Subdistrict, Aceh Tamiang Regency by using Simple Random Random Sampling technique, namely 66 mothers who had children under five. Chi Square test and logistic regression were used to analyze the data.Based on the results of the study note that the Infant Mortality Rate (IMR) is related to families participating in Family Planning $(p=$ $0.020)$, mothers giving birth in health facilities $(p=0.024)$, infants receive complete basic immunizations $(p=0.006)$, utilization (breast milk) exclusive $(p=0.038)$, monitoring of
\end{abstract}


toddler growth $(p=0,000)$. Based on the results of the study, it can be concluded that the factors related to Infant Mortality Rate (IMR) are families who participate in Family Planning, mothers deliver at health facilities, infants get complete basic immunizations, exclusive use (ASI), monitoring the growth of infants.So that the suggestions in this research are expected to be able to be material and input in the policy making of the Healthy Indonesia program with the Family Approach that health is a community right.

\section{Keywords: Healthy Indonesia Program Policies, IMR}

\section{PENDAHULUAN}

Program Indonesia Sehat juga merupakan salah satu program yang bertujuan untuk meningkatkan kualitas hidup manusia Indonesia, meningkatkan derajat kesehatan dan status gizi masyarakat melalui upaya kesehatan dan pemberdayaan masyarakat yang didukung dengan perlindungan finansial dan pemerataan pelayanan kesehatan(Fau, Nasution, \& Hadi, 2019).Kebijakan pembangunan kesehatan tahun 2015-2019 difokuskan pada penguatan upaya kesehatan dasar (Primary Health Care) yang berkualitas terutama melalui peningkatan jaminan kesehatan, peningkatan akses dan mutu pelayanan kesehatan dasar dan rujukan yang didukung dengan penguatan sistem kesehatan dan peningkatan pembiayaan kesehatan(Indonesia, 2016).

Berdasarkan data Kementerian Kesehatan Republik Indonesia tahun (2018), angka Kematian Neonatal (AKN) tetap sama yakni 19/1000 kelahiran, sementara untuk Angka Kematian Paska Neonatal (AKPN) terjadi penurunan dari 15/1000 menjadi 13/1000 kelahiran hidup, dan angka kematian anak balita juga turun dari 44/1000 menjadi 40/1000 kelahiran hidup. Penyebab kematian pada kelompok perinatal adalah Intra Uterine Fetal Death (IUFD), yakni sebanyak 29,5\% dan Berat Bayi Lahir Rendah (BBLR) sebanyak 11,2\%(Kesehatan, 2015).

Upaya pencapaian prioritas pembangunan kesehatan tahun 2015-2019 dalam Program Indonesia Sehat dilaksanakan dengan mendayagunakan segenap potensi yang ada, baik dari pemerintah pusat, provinsi, kabupaten/kota, maupun masyarakat.Hal ini berarti faktor keadaan ibu sebelum dan selama kehamilan sangat menentukan kondisi bayinya(Fau et al., 2019). Tantangan ke depan adalah mempersiapkan calon ibu agar benar-benar siap untuk hamil dan melahirkan serta menjaga agar terjamin kesehatan lingkungan yang mampu melindungi bayi dari infeksi.Pendekatan keluarga adalah salah satu cara Puskesmas untuk meningkatkan jangkauan sasaran dan mendekatkan/meningkatkan akses pelayanan kesehatan di wilayah kerjanya dengan mendatangi keluarga. Puskesmas tidak hanya menyelenggarakan pelayanan kesehatan di dalam gedung, melainkan juga keluar gedung dengan mengunjungi keluarga di wilayah kerjanya(Kalangie, 1994).

Pendekatan keluarga merupakan salah satu cara Puskesmas untuk meningkatkan jangkauan sasaran dan mendekatkan/meningkatkan akses pelayanan kesehatan di wilayah kerjanya dengan mendatangi keluarga. Puskesmas tidak hanya menyelenggarakan pelayanan kesehatan di dalam gedung, melainkan juga keluar gedung dengan mengunjungi keluarga di wilayah kerjanya. Pendekatan keluarga yang dimaksud dalam pedoman umum ini merupakan pengembangan dari kunjungan rumah oleh Puskesmas dan perluasan dari upaya Perawatan Kesehatan Masyarakat (Perkesmas), yang meliputi kegiatan berikut. dan manajemen Puskesmas.Berdasarkan indikator tersebut, dilakukan penghitungan Indeks Keluarga Sehat (IKS) dari setiap keluarga. Berdasarkan data Kementerian Kesehatan RI tahun 2018 diketahui bahwa kunjungan keluarga secara nasional telah meningkat, Dari 65.588.400 keluarga di Indonesia, sebanyak 17.651.605 keluarga yang telah mendapatkan kunjungan keluarga.Dalam pelaksanaan pendekatan keluarga ini tiga hal berikut harus diadakan atau dikembangkan, misalnya flyer tentang Kehamilan dan Persalinan untuk keluarga yang ibunya sedang hamil, Flyer tentang Pertumbuhan Balita untuk keluarga yang mempunyai balita, Flyer tentang Hipertensi untuk mereka yang menderita hipertensi, dan lain-lain(Kesehatan, 2015). 
Berdasarkan survey awal yang dilakukan oleh peneliti di Kecamatan Karang Baru Kabupaten Aceh Tamiang tahun 2019, dengan melihat data sekunder dari Dinas Kesehatan Kabupaten Aceh Tamiang yang masuk per April 2019 yaitu sekitar 40\% dari total jumlah penduduk di Kabupaten Aceh Tamiang, diketahui bahwa adapun Pencapaian Program PISPK yaitu sebagai berikut: 1) indikator penggunaan sarana air bersih telah mencapai 96,2\%; 2) Bayi mendapatkan imunisasi dasar lengkap telah mencapai 92,9\%; 3) Keluarga memiliki akses/menggunakan jamban keluarga telah mencapai telah mencapai 96,9\% ; 4) Persalinan Ibu di fasilitas pelayanan kesehatan telah mencapai 95,5\%; 5) Pertumbuhan Balita dipantau telah mencapai 81,3\%; 6) Bayi mendapatkan ASI Eksklusif telah mencapai 66,4 \%; 7) Keluarga sudah menjadi anggota JKN telah mencapai 89,3\%; 8) Keluarga mengikuti program KB telah mencapai 59,1\%; 9) Anggota keluarga tidak ada yang merokok telah mencapai $37,6 \%$; 10) Penderita TB Paru yang berobat sesuai standar telah mencapai $30,2 \%$; 11) Penderita hipertensi yang berobat teratur telah mencapai $23,2 \%$; 12) Penderita gangguan jiwa berat, diobati dan tidak ditelantarkan telah mencapai 16,7\%(Tamiang, 2019). Tujuan penelitian ini adalah untuk menganalisis hubungan kebijakan Program Indonesia Sehat dengan Pendekatan Keluarga terhadap Angka Kematian Bayidi Kecamatan Karang Baru KabupatenAcehTamiang.

\section{BAHAN DAN METODE}

Penelitian survei analitik dengan rancangan cross sectional study. Penelitian ini dilakukan di Kecamatan Karang Baru Kabupaten Aceh Tamiang dan dilaksanakan pada bulan September sampai dengan Oktober 2019.Populasi dalam penelitian ini adalah seluruh Kepala Keluarga yang terdaftar di di Kecamatan Karang Baru Kabupaten Aceh Tamiang yaitu sebanyak 3.298 Kepala Keluargadan besar sampel ditentukan dengan menggunakan teknik pengambilan sampel secara simple random sampling sebanyak 66 kepala keluarga. Metode pengumpulan data dalam penenlitian ini adalah dengan menggunakan teknik observasi. Adapun instrumen atau alat pengumpulan data yang digunakan peneliti untuk mengumpulkan data penelitian yaitu dengan menggunakan lembar kuesioner dan melakukan wawancara secara mendalam. Analisis data dilakukansecara univariat, bivariat (chi-square), analisis multivariat yang tepat untuk menganalisa data tersebut adalah menggunakan uji regresi logistik.

\section{HASIL}

Berdasarkan tabel 1 diketahui bahwa dari 66 responden, sebagian besar responden berumur 26-35 tahun yaitu sebanyak 39 (59,09\%) responden. Berdasarkan pendidikan diketahui bahwa dari 66 responden, sebagian besar responden berpendidikan SMA yaitu sebanyak 28 (42,43\%) responden. Berdasarkan pekerjaan diketahui bahwa dari 66 responden, sebagian besar responden memiliki pekerjaan sebagai IRT yaitu sebanyak 21 $(31,82 \%)$ responden. 
Tabel1.

Distribusi Karakteristik Responden di Kec. Karang Baru Kab. Aceh Tamiang

\begin{tabular}{ccc}
\hline Kelompok Umur (Tahun) & $\mathbf{n}$ & $\%$ \\
\hline $26-35$ & 39 & 59,09 \\
$36-45$ & 27 & 40,91 \\
\hline Pendidikan & & \\
\hline SD & 6 & 9,09 \\
SMP & 12 & 18,18 \\
SMA & 28 & 42,43 \\
D3 & 8 & 12,12 \\
D4 & 7 & 10,61 \\
S1 & 5 & 7,57 \\
\hline Pekerjaan & & \\
Petani & 11 & 16,67 \\
Wiraswasta & 16 & 24,24 \\
IRT & 21 & 31,82 \\
PNS & 18 & 27,27 \\
\hline Total & 66 & 100 \\
\hline
\end{tabular}

Untuk mengetahui hubungan Pendekatan Keluarga pada keluarga yang mengikuti Keluarga Berencana (KB) terhadap Angka Kematian Bayi (AKB) di Kecamatan Karang Baru Kabupaten Aceh Tamiang Tahun 2019, dapat dilihat pada tabel dibawah ini:

Tabel 2.

Hubungan Pendekatan Keluarga pada Keluarga Yang Mengikuti Keluarga Berencana (KB) Terhadap Angka Kematian Bayi (AKB) di Kec. Karang Baru Kab Aceh Tamiang

\begin{tabular}{|c|c|c|c|c|c|c|c|c|c|}
\hline \multirow{3}{*}{$\begin{array}{l}\text { Keluarga } \\
\text { Berencana }\end{array}$} & \multicolumn{6}{|c|}{ Angka Kematian Bayi } & OR & $95 \% \mathrm{Cl}$ & \multirow[t]{2}{*}{$\mathrm{P}$ value } \\
\hline & \multicolumn{2}{|c|}{$\begin{array}{c}\text { Risiko } \\
\text { Meningkat }\end{array}$} & \multicolumn{2}{|c|}{$\begin{array}{l}\text { Risiko } \\
\text { Menurun }\end{array}$} & \multicolumn{2}{|c|}{ Total } & \multirow{5}{*}{0,810} & \multirow{5}{*}{$\begin{array}{l}0,304- \\
32,154\end{array}$} & \\
\hline & $\mathrm{n}$ & $\%$ & $\mathrm{n}$ & $\%$ & $\mathrm{n}$ & $\%$ & & & \\
\hline Tidak & 14 & 40,00 & 21 & 60,00 & 35 & 100 & & & \\
\hline $\mathrm{Ya}$ & 14 & 45,16 & 17 & 54,84 & 31 & 100 & & & 0,010 \\
\hline Total & 28 & 42,42 & 38 & 57,58 & 66 & 100 & & & \\
\hline
\end{tabular}

Berdasarkan tabel 2 diketahui bahwa dari 66 responden yang diteliti, sebagian besar responden tidak mengikuti Keluarga Berencana yaitu sebanyak $35(53,03 \%)$ responden. Dari 35 (53,03\%) responden tersebut, ada sebanyak 14 (40,00\%) responden tidak mengikuti Keluarga Berencana (KB) dan mengalami risiko peningkatan angka kematian bayi, dan sebanyak $21(360,00 \%)$ responden tidak mengikuti Keluarga Berencana (KB) dan mengalami penurunan angka kematian bayi.Berdasarkan hasil perhitungan di atas diketahui bahwa hasil uji statistik diperoleh nilai pada baris OR yaitu $0,810(95 \% \mathrm{Cl}: 0,304-2,154)$ yang artinya responden yang tidak mengikuti program keluarga berencana kemungkinan 0,810 kali akan mengalami risiko peningkatan angka kematian bayi dari pada responden yang mengikuti program keluarga berencana. Nilai $p$ significancy yaitu 0,010 sehingga $p<0,05$. Sehingga dapat disimpulkan bahwa ada hubungan pendekatan keluarga pada keluarga yang mengikuti Keluarga Berencanaterhadap Angka Kematian Bayi. 
Tabel 3.

Hubungan Pendekatan Keluarga Pada Ibu Melakukan Persalinan di Fasilitas Kesehatan Terhadap Angka Kematian Bayi (AKB) di Kec. Karang Baru Kabupaten Aceh Tamiang

\begin{tabular}{|c|c|c|c|c|c|c|c|c|c|}
\hline \multirow{3}{*}{$\begin{array}{l}\text { Persalinan di } \\
\text { Fasilitas } \\
\text { Kesehatan }\end{array}$} & \multicolumn{6}{|c|}{ Angka Kematian Bayi } & \multirow[t]{2}{*}{ OR } & \multirow[t]{2}{*}{$95 \% \mathrm{Cl}$} & \multirow[b]{2}{*}{$\mathrm{P}$ value } \\
\hline & \multicolumn{2}{|c|}{$\begin{array}{c}\text { Risiko } \\
\text { Meningkat }\end{array}$} & \multicolumn{2}{|c|}{$\begin{array}{c}\text { Risiko } \\
\text { Menurun }\end{array}$} & \multicolumn{2}{|c|}{ Total } & & & \\
\hline & $n$ & $\%$ & $\mathrm{n}$ & $\%$ & $n$ & $\%$ & & & \\
\hline Tidak & 14 & 38,89 & 22 & 61,11 & 36 & 100 & 0,727 & $\begin{array}{l}0,273- \\
1,941\end{array}$ & 0,024 \\
\hline $\mathrm{Ya}$ & 14 & 46,67 & 16 & 53,33 & 30 & 100 & & & \\
\hline Total & 28 & 42,42 & 38 & 57,58 & 66 & 100 & & & \\
\hline
\end{tabular}

Berdasarkan tabel 3 diketahui bahwa dari 66 responden yang diteliti, sebagian besar responden tidak melakukan persalinan di fasilitas kesehatan yaitu sebanyak $36(54,54 \%)$ responden. Dari $36(54,54 \%)$ responden tersebut, ada sebanyak 14 (38,89\%) responden tidak melakukan persalinan di fasilitas kesehatan dan mengalami risiko peningkatan angka kematian bayi, dan sebanyak $22(61,11 \%)$ responden tidak melakukan persalinan di fasilitas kesehatan dan mengalami penurunan angka kematian bayi. Berdasarkan hasil perhitungan di atas diketahui bahwa hasil uji statistik diperoleh nilai pada baris OR yaitu $0,727(95 \% \mathrm{Cl}: 0,273-1,941)$ yang artinya responden yang tidak melakukan persalinan di fasilitas pelayanan kesehatan kemungkinan 0,727 kali akan mengalami risiko peningkatan angka kematian bayi dari pada responden yang melakukan persalinan di fasilitas pelayanan kesehatan. Nilai $p$ significancy yaitu 0,024 sehingga $p<0,05$. Sehingga dapat disimpulkan bahwa ada hubungan pendekatan keluarga pada ibu melakukan persalinan di fasilitas kesehatan terhadap Angka Kematian Bayi.

Tabel 4.

Analisis Regresi Logistik

\begin{tabular}{lrrrr}
\hline \multicolumn{1}{c}{ Variabel } & B & $\begin{array}{r}\text { P } \\
\text { vlue }\end{array}$ & $\begin{array}{r}\text { Exp } \\
\text { (B)OR }\end{array}$ & 95\%Cl for Exp(B) \\
\hline $\begin{array}{l}\text { Keluarga Berencana } \\
\text { (KB) }\end{array}$ & 0,120 & 0,017 & 1,128 & $0,247-4,047$ \\
$\begin{array}{l}\text { Melakukan } \\
\text { persalinan di fasilitas } \\
\text { kesehatan }\end{array}$ & 0,203 & 0,035 & 1,226 & $0,247-4,052$ \\
& & & & \\
\hline
\end{tabular}

Berdasarkan tabel 4 di atas dapat dilihat bahwa analisis regresi logistik menghasilkan secara bersama-sama hanya satu variabel yang paling dominan berpengaruh terhadap Angka Kematian Bayi (AKB) di Kecamatan Karang Baru Kabupaten Aceh Tamiang Tahun 2019 yaitu variabelkeluargaberencana, dengan signifikan 0,017 ( $p$ value $<0,05$ ), $O R=0,128$ $(95 \% \mathrm{Cl}=0,247-4,047)$ artinya responden yang tidak melakukan keluargaberencana mempunyai peluang 0,128 kali akan terjadi pencegahanpeningkatan angka kematian bayidibandingkan dengan responden yang melakukan keluargaberencana. Nilai koefisien B yaitu 2,334 bernilai positif yang artinya semakin banyak responden yang tidak melakukankeluargaberencana, maka semakin tinggi angka kematian bayidi Kecamatan Karang Baru Kabupaten Aceh Tamiang. 


\section{PEMBAHASAN}

Berdasarkan hasil penelitian diketahui bahwa di Kecamatan Karang Baru Kabupaten Aceh Tamiang, diketahui bahwa masih banyak masyarakat yang belum menggunakan KB atau sudah pernah menggunakan KB namun sudah tidak melanjutkannya. Masalah ini terjadi masih banyak masyarakat yang belum mengetahui tujuan serta manfaat dari KB itu sendiri. Padahal Program Keluarga Berencana memiliki makna yang sangat strategis, komprehensif dan fundamental bagi manusia Indonesia yang sehat dan sejahtera Pembangunan keluarga adalah upaya mewujudkan keluarga berkualitas yang hidup dalam lingkungan yang sehat. Setiap anggota keluarga memiliki peran dan fungsinya masingmasing untuk mempertahankan kondisi kesehatan didalam keluarga.Kondisi kesehatan yang dipertahankan mencakup pencegahan, perawatan, pemeliharaan, termasuk upaya membangun hubungan timbalbalik antara keluarga dengan fasilitas kesehatan. Salah satunya adalah dengan mengikuti KB(Yustisia, 2015).

Implementasi pelaksanaan kegiatan Keluarga Berencana dijabarkan kedalam tiga hal sebagai berikut: Peningkatan pengetahuan, sikap dan perilaku keluarga, dan upaya masyarakat terhadap penanggulangan masalah kesehatan reproduksi dan kelangsungan hidup ibu, bayi dan anak. Kegiatan ini dirancang untuk meningkatkan pengetahuan,sikap, dan prilaku keluarga serta masyarakat terhadap penanggulangan masalah kesehatan reproduksi dan kelangsungan hidup, ibu, bayi dan anak melalui pembinaan program KB(Indonesia, 2016).

Hal ini sejalan dengan Program Indonesia Sehat merupakan salah satu program dari Agenda ke-5 Nawa Cita, yaitu Meningkatkan Kualitas Hidup Manusia Indonesia. Program ini didukung oleh program sektoral lainnya yaitu Program Indonesia Pintar, Program Indonesia Kerja, dan Program Indonesia Sejahtera. Program Indonesia Sehat selanjutnya menjadi program utama Pembangunan Kesehatan yang kemudian direncanakan pencapaiannya melalui Rencana Strategis Kementerian Kesehatan Tahun 2015-2019, yang ditetapkan melalui Keputusan Menteri Kesehatan R.I. Nomor HK.02.02/Menkes/52/2015(Indonesia, 2016).

Berdasarkan asumsi peneliti, pelayanan program Keluarga Berencana (KB) harus lebih digalakkan lagi, misalnya dengan cara rutin melakukan penyuluhan tentang $\mathrm{KB}$, mendata warga dan memberikan pendidikan tentang KB. Dengan adanya kebijakan tentang KB, maka sedikit banyaknya angka kematian ibu dan bayi akan ditekan, karena hal ini berkaitan dengan program MDGs yang juga ditujukan untuk mendukung pencapaian target Millenium Development Goals (MDGs) terutama point 5b mengenai Angka Kematian lbu (AKI) melalui peningkatan kualitas dan cakupan sasaran pelayanan keluarga .

Ketentuan persalinan harus dilakukan di fasilitas pelayanan kesehatan merupakan kebijakan Pemerintah dalam menjaga kesehatan ibu dan mengurangi angka kematian ibu. Di samping adanya pengecualian pada kondisi tertentu dapat dilakukan di luar Fasyankes. Permenkes No. 97 Tahun 2014 Pasal 14 ayat (1) yang berbunyi persalinan harus dilakukan di fasilitas pelayanan kesehatan (Fasyankes) tidak berarti adanya larangan untuk melakukan persalinan di luar Fasyankes(Kusumawati, 2016).Berdasarkan hasil penelitian diketahui bahwa masyarakat di kecamatan Karang Baru Kabupaten Aceh Tamiang, hampir sebanding dengan yang tidak melakukan pemeriksaan kehamilan pada bidan setiap bulan di posyandu atau puskesmas terdekat. Padahal dengan kerutinan masyarakat melakukan pemeriksaan maka dapat diketahui keadaan janin serta untuk mengukur tekanan darah, meminta obat dan vitamin. Sehingga apabila ada masalah dengan janin maka bidan atau petugas kesehatan lainnya dapat segera meruju ibu tersebut ke fasilitas kesehatan yang memadai untuk menghindari adanya abortus. Sedangkan apabila seseorang melakukan pemeriksaan pada dukun atau penolong persalinan lainnya diluar medis maka akan berbahaya bagi keselamatan ibu dan bayi. Selain itu pada awal kehamilan sering dilakukan pemerikasaan kepada dukun begitu terlambat datang bulan untuk memastikan kehamilan dan untuk pijat (urut). Berdasarkan hasil observasi peneliti, hal menarik yang ditemukan di kecamatan Karang Baru Kabupaten Aceh Tamiangadalah ketika persalinan yang dihubungi pertama kali adalah dukun. Alasannya, karena dukun diibaratkan sebagai penolong pertama, setelah 
dukun datang kemudian menghubungi bidan jika ada kesulitan dalam persalinan. Selain itu mereka juga mengatakan keputusan memanggil dukun adalah kesepatan bersama antara suami -istri dan juga keluarga.

Dari beberapa penemuan diatas diketahui pemeriksaan kehamilan pada bidan telah menjadi rutinitas masyarakat di kecamatan Karang Baru Kabupaten Aceh Tamiang, namun demikian masyarakat yang melakukan pemeriksaan pada dukun. Hal ini dilakukan karena adanya kemudahan dari segi jarak dan biaya, juga manfaat yang tidak didapat dari dukun. Namun tidak demikian pada saat persalinan sebagian besar ibu lebih memilih memanggil dukun, dan bidan dipanggil jika terjadi penyulit dalam persalinan. Hal ini karena karena tempat tinggal dukun lebih dekat dan biayanya terjangkau. Selain itu ibu mempunyai pengalaman persalinan pada dukun yang lebih banyak dan hasilnya juga baik. Senada dengan hal diatas, hasil penelitian Eryando di Tangerang tahun 2006 diketahui bahwa salah satu alasan ibu menggunakan jasa Paraji / dukun untuk periksa kehamilan dan persalinan adalah karena dukun memiliki kemampuan untuk urut yang tidak dimiliki oleh bidan(Eryando, 2007).Kebiasaan lain yang diungkapkan oleh masyarakat di kecamatan Karang Baru Kabupaten Aceh Tamiangbahwa seorang bayi baru lahir tidak boleh keluar rumah sebelum mencari hari -hari baik, dan biasanya dilakukan pada usia 3 bulan keatas. Dari hasil penulusuran dilapangan ditemukan masih banyak bayi dan balita yang tidak mendapatkan imunisasi pada umur kurang dari 3 bulan. Dengan kondisi ini tentu perlu ada tindak lanjut dari pemerintah khususnya di wilayah Sandang Pangan yang masih kental dalam menjaga adat dan tradisi. Walaupun terasa sulit karena menyangkut tradisi dan kepercayaan masyarakat tetapi perlu untuk dicarikan solusi, dan ini tentu tidak hanya bisa dilakukan oleh bidan dan kepala puskesmas, selayaknya Dinas Kesehatan harus menindak lanjuti permasalahan ini.

Hasil observasi diketahui bahwa posyandu yang berada di tiap desa adalah tempat layanan kesehatan yang paling sering dikunjungi ibu hamil dalam rangka memeriksan kehamilan. Hal ini juga didukung kemudahan dari sisi jarak dan biaya, dimana untuk periksa hamil tidak dipungut biaya (gratis). Selain itu seluruh masyarakat menilai bahwa fasilitas layanan kesehatan berada dekat tempat tinggal mereka sehingga mudah dijangkau, walaupun ada diantara mereka yang belum pernah menggunakannya, misalnya pasangan bulin keluarga dari desa Sandang Pangan, alasannya karena tidak punya biaya dan merasa jarang sakit, kalaupun sakit mereka hanya mengobati menggunakan air doa dari dukun atau yang dibuat sendiri oleh suami. Namun demikian saat bersalin, sebagian besar responden mengatakan bidan tidak berada di tempat sehingga mereka beralih ke dukun, dimana biaya bersalin padadukun dirasakan lebih murah dan terjangkau.

Mengenai praktek pemanfaatan layanan Persalinan di kecamatan Karang Baru Kabupaten Aceh Tamiang, sebagian besar ibu hamil memang memeriksakan diri pada dukun dan juga rutin ke Posyandu. Namun saat melahirkan pihak yang dihubungi adalah dukun karena dukun tinggal dan menetap dikampung, sehingga paling mudah dijangkau. Selain itu masyarakat juga lebih memilih dukun karena ada keragu -raguan dari segi biaya, walaupun mereka telah memiliki kartu Indonesia Sehat. Hal ini dikarenakan selama ini untuk pemeriksaan umum di Puskesmas di Kecamatan Karang Baru Kabupaten Aceh Tamiangterkadang masyarakat masih harus mengeluarkan biaya tambahan walaupun memiliki kartu Jamkesmas.

Menurut asumsi peneliti, Bidan harus tinggal dan menetap didesa agar terjalin komunikasi dan terbina keakraban dengan warga binaanya. Memberikan penyuluhan yang intensif tentang persalinan yang bersih dan aman, dapat dirangkaikan dengan kegiatan arisan desa dan posyandu yang dilaksanakan tiap bulan. Bidan harus meningkatkan pelayanan kehamilan dengan mengunjungi ibu -ibu hamil yang tidak rutin periksa hamil. Selain itu dukun juga perlu diberi pembinaan dan pelatihan tentang cara pemeriksaan pada ibu hamil yang aman.Bidan harus mau memberikan pelayanan persalinan dengan mendatangi rumah ibu bersalin dan juga mengijinkan suami dan keluarga untuk mendampingi ibu selama proses persalinan. Agar sejalan dengan tujuan PIS-PK Kunjungan rumah (keluarga) dilakukan secara terjadwal dan rutin, dengan memanfaatkan data dan informasi dari Profil Kesehatan Keluarga (family folder). Dengan demikian, pelaksanaan 
upaya Perawatan Kesehatan Masyarakat (Perkesmas) harus diintengrasikan ke dalam kegiatan pendekatan keluarga. Dalam menjangkau keluarga, Puskesmas tidak hanya mengandalkan upaya kesehatan berbasis masyarakat (UKBM) yang ada sebagaimana selama ini dilaksanakan, melainkan juga langsung berkunjung ke keluarga. Perlu diperhatikan, bahwa pendekatan keluarga melalui kunjungan rumah ini tidak berarti mematikan UKBM-UKBM yang ada, tetapi justru untuk memperkuat UKBM-UKBM yang selama ini dirasakan masih kurang efektif.

Hal ini sejalan dengan penelitian Purwanto, dkk (2013) dengan judul penelitian "Implementasi Kebijakan Program Keluarga Harapan (PKH) dalam Memutus Rantai Kemiskinan (Kajian di Kecamatan Mojosari Kabupaten Mojokerto)"menunjukkan bahwa secara umum pelaksanaan PKH di Kecamatan Mojosari ini sudah berjalan dengan cukup baik. Ini dapat dilihat dari setiap tahapan proses pelaksanaannya yang berjalan lancar. Apabila diihat dari keadaan penerima bantuan PKH tersebut mereka menggunakannya untuk membantu kondisi sosial dan pendidikan anak-anak RTSM, membantu biaya kesehatan \& gizi ibu hamil, ibu nifas, dan anak di bawah 6 tahun dari RTSM, serta menyadarkan peserta $\mathrm{PKH}$ akan pentingnya layanan pendidikan dan Kesehatan(Purwanto, Sumartono, \& Makmur, 2013).

Bidan harus lebih intensif mengadakan pendekatan dengan masyarakat, agar mereka menjadi terbiasa dengan keberadaan dan pelayanan yang diberikan bidan. Dalam memberikan layanan persalinan bidan dapat melibatkan dukun untuk member air doa -doa atau tidak melarang ibu untuk mengkonsumsi air doa -doa dari dukun. hal ini untuk memberikan ketenangan pada ibu. Peningkatan pengetahuan tidak hanya dilakukan pada ibu tetapi juga pada suami dan keluarga ibu bersalin. Peningkatan pengetahuan tentang hal -hal yang mempengaruhi kesehatan ibu hamil dan janin yang dikandungnya. Bidan harus menyediakan waktu lebih banyak untuk mengunjungi yang bekerj Berdasarkan tabel1diketahui bahwa dari 66 responden, sebagian besar responden berumur 26-35 tahun yaitu sebanyak $39(59,09 \%)$ responden. Berdasarkan pendidikan diketahui bahwa dari 66 responden, sebagian besar responden berpendidikan SMA yaitu sebanyak $28 \quad(42,43 \%)$ responden. Berdasarkan pekerjaan diketahui bahwa dari 66 responden, sebagian besar responden memiliki pekerjaan sebagai IRT yaitu sebanyak $21 \quad(31,82 \%)$ responden.

a dikebun. Untuk itu perlu dukungan pemda untuk menyediakan insentif tambahan. Hasil penelitian ini menunjukkan bahwa seluruh variabel (lima variabel) berhubungan dengan Angka Kematian Bayi (AKB) di Kecamatan Karang Baru Kabupaten Aceh Tamiang. Hal ini mengandung implikasi agar kedepannya pihak-pihak terkait, seperti masyarakat dan petugas kesehatan di Kecamatan Karang Baru Kabupaten Aceh Tamiang dapat memperhatikan kebijakan program PIS PK agar dilaksanakan dengan semaksimal mungkin.

\section{KESIMPULAN DAN SARAN}

Penelitian ini diperoleh kesimpulan bahwa ada hubungan pendekatan keluarga pada keluarga yang mengikuti keluarga berencanadan ibu melakukan persalinan di fasilitas kesehatanterhadap angka kematian bayidi Kecamatan Karang Baru Kabupaten Aceh Tamiang.Diharapkandenganpendekatan keluarga dan benar-benar untuk melaksanakan kebijakan program kementerian kesehatan tersebut, serta memiliki komitmen yang tinggi didalam melaksanakan kebijakan program indonesia sehat melalui pendekatan keluarga tersebut.

\section{UCAPAN TERIMA KASIH}

Kami mengucapkan terima kasih kepada responden, pemerintah dan kepala Puskesmas Kecamatan Karang Baru Kabupaten Aceh. 


\section{DAFTAR PUSTAKA}

Eryando, T. (2007). Aksesibilitas Kesehatan Maternal di Kabupaten Tangerang, 2006. Makara, Kesehatan, 11(2), 76-83.

Fau, S. Y., Nasution, Z., \& Hadi, A. J. (2019). Faktor Predisposisi Ibu Usia Remaja Terhadap Pemberian ASI Eksklusif pada Bayi di Kecamatan Luahagundre Maniamolo Kabupaten Nias Selatan. MPPKI (Media Publikasi Promosi Kesehatan Indonesia): The Indonesian Journal of Health Promotion, 2(3), 165-173.

Indonesia, K. K. R. (2016). Pedoman umum program Indonesia Sehat dengan pendekatan keluarga. Jakarta: Kementerian Kesehatan RI.

Kalangie, N. S. (1994). Kebudayaan dan kesehatan: pengembangan pelayanan kesehatan primer melalui pendekatan sosiobudaya. Megapoin, Divisi dari Kesaint Blanc.

KEMENKES, R. I., \& Indonesia, K. K. R. (2013). Riset kesehatan dasar 2013. Badan Penelitian Dan Pengembangan Kementerian Kesehatan RI, Jakarta.

Kesehatan, K. (2015). Rencana strategis kementerian kesehatan. Jakarta. Kementerian Kesehatan.

Kusumawati, F. (2016). PELAKSANAAN KELAS IBU HAMIL SEBAGAI UPAYA MENURUNKAN ANGKA KEMATIAN IBU DITINJAU DARI PERATURAN MENTERI KESEHATAN NO. 97 TAHUN 2014 TENTANG PELAYANAN KESEHATAN MASA HAMIL DI PUSKESMAS KOTA SEMARANG. UNIKA SOEGIJAPRANATA.

Purwanto, S. A., Sumartono, S., \& Makmur, M. (2013). Implementasi Kebijakan Program Keluarga Harapan (PKH) Dalam Memutus Rantai Kemiskinan (Kajian di Kecamatan Mojosari Kabupaten Mojokerto). WACANA, Jurnal Sosial Dan Humaniora, 16(2), 79_ 96.

Tamiang, D. A. (2019). Profil Kesehatan Kabupaten Aceh Tamiang Tahun 2019. Jantho: Dinas Kesehatan Kabupaten Aceh Tamiang.

Yustisia, T. V. (2015). Undang-Undang No 23 Tahun 2014 tentang Pemerintahan Daerah dan Perubahannya. VisiMedia. 